\title{
Review on Typical Ingredients For Ammonium Perchlorate Based Solid Propellant
}

\author{
Amir Aziz ${ }^{1, a}$, Rizalman Mamat ${ }^{2}$, Wan Khairuddin Wan $\mathrm{Ali}^{3}$, \\ Mohd Rozi Mohd Perang ${ }^{4}$ \\ 1, 2 Faculty of Mechanical Engineering, UMP \\ ${ }^{3}$ Department of Aeronautical Engineering, Faculty of Mechanical Engineering, UTM \\ ${ }^{4}$ Automotive Development Centre, Faculty of Mechanical Engineering, UTM \\ aamiraziz@ump.edu.my
}

Keywords: Ammonium perchlorate, solid propellant, composition

\begin{abstract}
Ammonium perchlorate (AP) based solid propellant is a modern solid rocket propellant used in various applications. The combustion characteristics of AP based composite propellants were extensively studied by many research scholars to gain higher thrust. The amount of thrust and the thrust profile, which may be obtained from a specific grain design, is mainly determined by the propellant composition and the manufacturing process that produces the solid propellant. This article is intended to review and discuss several aspects of the composition and preparation of the solid rocket propellant. The analysis covers the main ingredients of AP based propellants such as the binder, oxidizer, metal fuel, and plasticizers. The main conclusions are derived from each of its components with specific methods of good manufacturing practices. In conclusion, the AP based solid propellant, like other composite propellants is highly influenced by its composition. However, the quality of the finished grain is mainly due to the manufacturing process.
\end{abstract}

\section{Introduction}

Ammonium perchlorate (AP) based propellant is typically used in rocket propulsion applications, such as missiles and rocket launchers. The main advantages of AP based propellants are good specific impulses, high reliability, and a relatively simple manufacturing process. Because of these performance attributes, AP based propellant is regularly used in booster applications, such as space exploration rockets, aircraft ejection, and international ballistic missiles.

In practice, there are many parameters to be considered before a solid propellant can be manufactured. The parameters include the ingredients and the steps of manufacturing. Holmes et al. [1] reported that there are at least ten different ingredients used in producing a solid propellant. While Ramohalli et al. [2] mentioned that in manufacturing propellants there would be at least 30 steps that have to be followed.

However, there are four typical ingredients for solid propellants, which consist of a polymeric binder, a curing agent as an additive, an oxidizer, and metal fuel. Thus, with only these ingredients, a typical solid propellant could be produced and tested. This paper describes the four main compositions of the typical ingredients that are selected for solid propellant creation, which are Hydroxyl terminated polybutadiene (HTPB) as the binder, aluminum (Al) as the metal fuel, ammonium perchlorate (AP) as the oxidizer, and Isophorone diisocyanate (IPDI) as the curing agent.

\section{Hydroxyl Terminated Polybutadiene (HTPB)}

The first ingredient in a composite propellant is the binder. The binder provides the structural glue or matrix in which solid loadings are held. A common binder used in a composite propellant is an elastomeric binder. These binders include polyesters, polysulfide, polybutadiene acrylonitrile 
(PBAN), carboxyl terminated polybutadiene (CTPB), and Hydroxyl terminated polybutadiene (HTPB).

The HTPB binder was found in early 1970 and has been used in composite solid propellants for rockets and missile applications [9, 17]. The HTPB is a yellowish liquid, polymeric binder and is normally produced by free radical polymerization. A study by K. B. Catherine et al. [12, 17-19] used the HTPB binder that was manufactured by the free-radical polymerization of butadiene using hydrogen peroxide as an initiator. Different manufacturers may use different methods that lend different properties to HTPB. Currently it has become the best binder available because of its processability and higher energy content compared to other binders [20]. Although the CTPB binder has good mechanical properties, it has problems with aging characteristics [21]. Most common polymers become soft at high temperatures and brittle at low temperatures. However, HTPB is able to demonstrate good mechanical properties at low temperatures and good aging characteristics [21].

Although HTPB is an inert binder [22, 23], curing it with isocyanate will form a polymeric binder, which has superior mechanical properties. There were only a few papers that discussed the amount of curing agents used in the respective research studies. Generally, HTPB can be cured using a different isocyanate, such as Toluene diisocyanate (TDI), Isophorone diisocyanate (IPDI), or diphenyl diisocyanate (DDI) $[12,24]$. By far, TDI and IPDI are the most commonly applied for cast-cured propellants. The chemical TDI has a low pot life, which is approximately 30 minutes compared to IPDI, which has a pot life of three to four days depending on the storage temperature. Pot life was defined by Carlton et al. [25] as the period of time for a propellant to begin to cure until it approaches a gel stage or solid. Kym et al. $[8,10]$ reported that, HTPB cured with IPDI melted slowly and mildly over a range of temperatures from $330-370^{\circ} \mathrm{C}$ and started to decompose at temperatures close to $500^{\circ} \mathrm{C}$. The chemical IPDI increases the burn rate at a low pressure and improves the plateau at a high pressure [10]. C.W. Fong et al. [26, 27] reported that DDI cured HTPB propellants produce lower burning rates compared to other isocyanates, such as IPDI or TDI. The combustion of DDI cured HTPB propellants are more endothermic than IPDI cured HTPB propellants.

\section{Aluminum (Al)}

The second ingredient in composite propellants is metal fuel. Metal fuel was added in composite propellants to enhance performance by increasing the combustion temperature. Twenty five years ago, almost every element in the periodic table was tested to investigate the possibilities for propellant formulation [20]. These included beryllium, zirconium, boron, magnesium, and aluminum (Al). Beryllium (Be) has a high heat of combustion and a low molecular weight combustion, but it has a highly toxic oxide that can cause fatal effects compared to Al. For Zirconium (Zr), combustion efficiency is poorer than $\mathrm{Al}$, and it has lower energy compared to $\mathrm{Al}$ and $\mathrm{Be}$. The problem for boron is that it is too expensive relative to aluminum when compared to performance. The addition of magnesium $(\mathrm{Mg})$ to a propellant would tend to decrease rather than increase the performance (Isp) [20].

Compared to others, Al is the best metal fuel because of the high heat of combustion, low cost, ready commercial availability, low degree of toxicity, and relatively high combustion efficiency. Aluminum has the symbol Al and atomic number 13. Aluminum is soft, durable, and lightweight with an appearance ranging from silvery to dull grey. In the usual form, Al is powder or dust and can damage the lungs if inhaled [28]. But in coarser forms like the powder, it is less dangerous. For a composite propellant, Al usually constitutes around $5 \%$ to $25 \%$ of the propellant weight [10] and acts as a metallic fuel and additive to enhance the performance of a rocket motor. The decomposition of $\mathrm{Al}$ produces a high combustion temperature. The combustion temperature increases approximately $15 \%$ by the addition of $10 \%$ of aluminum [29]. Al has a high heat capacity [30], which releases a large amount of energy that significantly expands the gases in the combustion chamber. As the gases expand, the pressure rises and forces the exhaust gases to escape through the 
nozzle. This is known as exit velocity. The higher exit velocity, in turn, raises the specific impulse of the motor.

However, a problem also arises from increasing the amount of Al. Although the combustion temperature increases, the molecular mass of the combustion products also increase due to the formation of aluminum oxide. As a result, the performance of rockets is significantly reduced [22]. Recently, rocket scientists have studied nanosizing or Ultra Fine Aluminum (UFAL) [references]. The UFAL was produced by an electro explosion [4] of aluminum wire in an inert medium, specifically argon, at nearly atmospheric pressure [6]. Ultra Fine Aluminum has a particle size of $0.1 \mu \mathrm{m}$ compared to the typical aluminum used in propellants at $30 \mu \mathrm{m}$. The advantages of UFAL are the ability to give high burning rates, the complete combustion, and higher energy propellant. The disadvantages of UFAL are the high cost and decreases in the energy of the propellant combustion because of the low content of metallic aluminum (high content of the oxide) [4].

\section{Ammonium perchlorate (AP)}

Another ingredient in composite propellant is the oxidizer, which can be referred to as the material that whose function is the supply of oxygen or oxidizing materials for deflagration of a solid propellant [25]. Some of the most common oxidizers include ammonium nitrate (AN), potassium nitrate $(\mathrm{KNO} 3)$, potassium perchlorate $(\mathrm{KClO} 4)$, sodium nitrate $(\mathrm{NaNO} 3)$, and lithium perchlorate (LiClO4). Nevertheless, these oxidizers produce a much lower Isp compared to AP, except for LiClO4, which is slightly lower than AP [20]. The problems with LiClO4 are hygroscopic and expensive. Although AN is hygroscopic, it was applied when rocket motors need to obtain low burning rates, low flame temperatures, and smokeless exhaust [25].

The proven and widely used oxidizer is ammonium perchlorate (AP), which replaced potassium perchlorate as an oxidizer in the late 1940s [32]. At room conditions, AP is a powder of white crystalline material with a density of approximately $1949 \mathrm{~kg} / \mathrm{m} 3$. Like other perchlorates, AP is a powerful oxidizer and was used as an oxidizer in various types of propellants and pyrolants (energetic materials that generate hot flames upon combustion) [22]. Two major reasons for AP's widespread use are its stability, resulting in safe munitions, and its ability to control a propellant's burning rate [33].

The particle sizes of AP can affect the manufacturing process and burning rate of a propellant. R.R miller et al. [34] reported a burning rate increase with decreasing particle size of AP. Sizes below 40 micrometres are considered hazardous because of easy ignitability and sometimes detonation [28]. For the application of composite propellants, AP usually constitutes around 59\% to $90 \%$ of the propellant weigh [20,35]. Theoretically, the performance of AP/HTPB propellant will decrease significantly when using a mass fraction of AP higher than $90 \%$ [20].

\section{Additives}

Another ingredient that is added in the composite propellants is additives. A small amount of additives are added in composite propellants for many purposes, such as altering the curing time, improving rheology properties for easier casting (plasticizers), altering burning rate (burn rate modifiers), improving bonding (bonding agents), improving the physical properties, or improving aging characteristics. D.H. Meyer [20] reported that small quantities of additives do not affect the performance (Isp) of the propellant.

Plasticizers were also known as pot life controllers. They were added to the propellant mixture to increase the plasticity and flow behaviour [12]. Increasing the level of plasticizer will reduce the viscosity of the binder. R. C. Matthew et al. [14], state that by adding $0.2 \%$ Tepanol (to act as a plasticizer) and two drops of Silicone Oil (a defoaming agent), the ease of production and physical strength of the propellant were increased without affecting the burn rate. While Rm. Muthiah et al. [36] reported that the most suitable plasticizers used with HTPB are DOA and IDP due to the ability 
to improve the processability and pot life of HTPB propellants. Works by several other researchers $[3,6,10$, and 12] used DOA as a plasticizer for composite propellants and accounts for around $1 \%$ to $5 \%$ of the propellant weight.

Lower burning rates could be achieved by adding a small amount of nitramine [21]. Shigeyuki et al. [37] reported that the addition of a ferric oxide catalyst enhances the burning rate and sustains the steady-state combustion. Works by Liang et al. [13] reported that the burning rate of AP composite propellants can be reduced by adding Ammonium oxalate (AO). It has the ability to increase the decomposition temperature and the activation energy of AP, which leads to a decrease in burning rates. Unfortunately, AO is a highly hygroscopic chemical and has the ability to absorb humidity from the air. As a result, the propellants produced have poor mechanical properties.

\section{Conclusion}

Ammonium perchlorate based solid propellants have drawn attention from many scientists for several reasons. Many scholars spend money and time to study the best compositions or ingredients to maximize the potential of AP based propellants. In conclusion, it has been found that every component plays a vital role for different aspects of the formulation. Therefore, before the propellant can be extensively manufactured, a thorough study should be conducted to ensure the best ingredients are used. The manufacturing techniques used to produce the propellant also play an important role in ensuring the final product fits the minimum requirements.

\section{Acknowledgments}

The authors gratefully acknowledge support for this work through the University Malaysia Pahang, the University Technology Malaysia, and the Ministry of Education Malaysia under the Research Acculturation Collaborative Effort for funding this project.

\section{References}

[1] Martin S. M. and Hughes E. H. Subatmospheric Burning Rates and Critical Diameters for Ap/Htpb Propellant. U.S. Army Ballistic Research Laboratory. 1989.

[2] Perez D. and Ramohalli K. Scientific Approach to Propellant Processing: Slurry Viscosity and Rheology. AIAA/SAE/ASME 27th Joint Propulsion Conference. June 24-27, 1991. Sacramento, CA: AlAA. 1991.

[3] Fitzgerald R. P., Brewster M. Q. Infrared Imaging of AP/HTPB Laminate Propellant Flames. Combustion and Flame. 154 (2008) 660-670.

[4] Abraham S., Hadassah A., Moshe K. and David H. The Effect of Nanosized Aluminum on Composite Propellant Properties. 41st AIAA/ASME/SAE/ASEE Joint Propulsion Conference \& Exhibit. July 10-13, 2005. Tucson, Arizona: AIAA. 2005.

[5] Makoto K. and Saeko Y. Burning Rate Characteristics of AP-based Composite Propellant Using Bimodal AP. 42nd AIAA/ASME/SAE/ASEE Joint Propulsion Conference \& Exhibit. July 912, 2006. Sacramento, California: AIAA. 2006.

[6] Jayaraman K., Anand K. V., Chakravarthy S. R. and Sarathi R. Effect of Nano-Aluminium in Plateau-Burning and Catalyzed Composite Solid Propellant Combustion. Combustion and Flame. 156 (2009) 1662-1673.

[7] Masafumi T., Yoshinori N., and Tomonari Y. Intrinsic Instability of AP Composite Propellants in an Intermediate Pressure Range. 41st Aerospace Sciences Meeting and Exhibit. January 6-9, 2003. Reno, Nevada: AIAA. 2003. 
[8] Price E.W., Chakravarthyf S.R., Sigman R.K., and Freeman J.M. Pressure Dependence of Burning Rate of Ammonium Perchlorate-Hydrocarbon Binder Solid Propellants. American Institute of Aeronautics and Astronautics, 1997.

[9] Mahanta A. K., Dharmsaktu I., and Pattnayak P. K. Rheological Behaviour of HTPB-Based Composite Propellant: Effect of Temperature and Pot Life on Casting Rate. Defence Science Journal. 57 (2007) 435-442

[10]Ide K.M. Composite Propellants with Bi-Plateau Burning Behaviour. Weapons Systems Division, Systems Sciences Laboratory. 2002.

[11]Krishnan S. and Rajesh K. K. Erosive Burning of Ammonium Perchlorate/HydroxylTerminated Polybutadiene Propellants under Supersonic Crossflows. 37th AIAA/ASME/SAE/ASEE Joint Propulsion Committee Conference and Exhibit. July 8-11, 2001. Salt Palace-Salt Lake City, Utah: AIAA. 2001.

[12] Jawalkar S. N., Mehilal, Ramesh K., Radhakrishnan K. K., Bhattacharya B. Studies on The Effect of Plasticiser and Addition of Toluene Diisocyanate at Different Temperatures in Composite Propellant Formulations. Journal of Hazardous Materials. 164 (2009) 549-554.

[13] Muhammad Mazhar I. and Wang L. Modeling The Moisture Effects of Solid Ingredients on Composite Propellant Properties. Aerospace Science and Technology. 10 (2006) 695-699.

[14] Matthew S., Radolphe C., Steven W., Thomas S., and Eric P. Performance of AP-Based Composite Propellant Containing Nanoscale Aluminum. 41st AIAA/ASME/SAE/ASEE Joint Propulsion Conference \& Exhibit. July 10-13, 2005. Tucson, Arizona: AIAA. 2005.

[15] Matthew S., Radolphe C., Steven W., Thomas S., and Eric P. Performance of AP-Based Composite Propellant Containing Nanoscale Aluminum. 41st AIAA/ASME/SAE/ASEE Joint Propulsion Conference \& Exhibit. July 10-13, 2005. Tucson, Arizona: AIAA. 2005.

[16] Tanaka M., Nakao C., and Hayakawa S. Combustion of Solid Propellants at Low Pressure. 36th AIAA/ASME/SAE/ASEE Joint Propulsion Conference \& Exhibit. 16-19 July, 2000. Huntsville, AL: AIAA. 2000.

[17] Korah Bina C., Kannan K. G. and Ninan K. N. DSC Study on The Effect of Isocyanates and Catalysts on The HTPB Cure Reaction. Journal of Thermal Analysis and Calorimetry. 78 (2004) 753-760.

[18] Catherine K. B., Krishnan K. and Ninan K. N. A DCS Study on Cure Kinetics of HTPB-IPDI Urethane Reaction. Journal of Thermal Analysis and Calorimetry. 59 (2000) 93-100.

[19] Vilart W.D., Menezes S.M.C., Seidl P.R. Hydroxyl-Terminated Polybutadiene Iv. Nmr Assignments of Three Main Hydroxylated End Groups. Polymer Bulletin. 38 (1997) 327-332.

[20] Meyer D.H. A Study of Propellants and Specific Impulse in Model Rocket Engines. National Association of Rocketry 1984.

[21]Aoki I. and Kubota N. History of Solid Propellant Development in Japan. 30th AIAA/ASME/SAE/ASEE Joint Propulsion Conference. June 27-29, 1994. Indianapolis: AIAA. 1994.

[22] Kubota, N. Propellants and Explosives. WILEY-VCH Verlag GmbH \& Co.KGa.A. 2001. 
[23] Seifolazadeh A. and Edrissi M. TA of HTPB Mixtures with Some of The Energetic MaterialsDetermination of Effective Factors. Journal of Thermal Analysis and Calorimetry. 76 (2004) 329333.

[24] Wingborg N. Increasing the Tensile Strength of HTPB With Different Isocyanates and Chain Extenders. Polymer Testing. 21 (2002) 283-287.

[25] Howard W. D. Solid Propellant Processing Factors in Rocket Motor Design. NASA. 1971.

[26]Fong C.W., Hamshere B.L,. and Hooper J.F. The Role of Binders in Plateau Burning HTPBAP Composite Propellants. Department of Defence, Defence Science and Technology Organization Weapons Systems Research Laboratory. 1985.

[27]Frederick Jr. R. A., John R., Xu W. and Xin F. Effect of Binder Curative On Combustion Processes. AlAA 26th Aerospace Sciences Meeting. January 11-14, 1988. Reno, Nevada: AIAA. 1988.

[28] Jones L. E. A Safety Manual for Experimental and Amateur Rocket Scientists. Rocket Science Books, California. 2003..

[29] Amir Aziz and Wan Khairuddin Wan Ali, Combustion Characteristics of AP Based Solid Rocket Propellant. 2011: Verlag Dr. Muller.

[30] Steinz J.A., Stang P.L., and Surmerfield M. The Burning Mechanism of Ammonium Perchlorate-Based Composite Solid Propellants. Princeton University Department Of Aerospace And Mechanical Sciences. 1969.

[31] Aluminum Powder. In Mallinckrodt Baker, I, ed. Material safety data Sheet. Philipsburg, NJ 08865, 1999.

[32] Hunley J. D. The History of Solid-Propellant Rocketry: What We Do and' Do Not Know (Invited Paper). 35th AIAA/ASME/SAE/ASEE Joint Propulsion Conference and Exhibit. June 2024, 1999. Los Angeles, CA: AIAA. 1999.

[33] Matthew L. G., Scott A. F. and Merrill W. B. Two-dimensional Modeling of AP Composite Propellants with Detailed Kinetics: Particle Size Effects. 42nd AIAA/ASME/SAE/ASEE Joint Propulsion Conference \& Exhibit. 9-12 July 2006. Sacramento, California: AIAA. 2006.

[34]Miller R. R. Effects of Particle Size on Reduced Smoke Propellant Ballistics. 18th AIAA/SAE/ASME Joint Propulsion Conference. June 21-23, 1982. Cleveland, Ohio: AIAA. 1982.

[35] Sutton G. P. Rocket Propulsion Element Sixth Edition. John Willy \& Sons, MIT 1992.

[36] Muthiah R., Somasundaran U. I., Verghese T. L. and Thornas V. A. Energetics and Compatibility of Plasticizers in Composite Solid Propellants. Defence Science Journal. 1989. 39: 147-155.

[37] Hayakawa S., Tanaka M. and Nakao C. An Effect of Oxidizer Particle Size on Combustion Stability in Composite Propellants. 36th AIAA/ASME/SAE/ASEE Joint Propulsion Conference \& Exhibit. July 16-19, 2000. Huntsville, AL: AIAA. 2000. 